\title{
Optimization of fermentation conditions for producing Indian rock bee (Apis dorsata) mead using response surface methodology
}

\author{
N. Srimeena*, S. Gunasekaran and R. Murugesan \\ Department of Agricultural Microbiology, Tamil Nadu Agricultural University, Coimbatore - 641003 (Tamil Nadu), \\ INDIA \\ *Corresponding author. E-mail: meenanagaiah@gmail.com \\ Received: May, 05, 2014; Revised received: August 17, 2014 ; Accepted: September 20, 2014
}

\begin{abstract}
Mead is a traditional drink which results from the alcoholic fermentation of diluted honey carried out by yeast (Saccharomyces cerevisiae KF233529). The present investigation was carried out for the optimization of fermentation parameters for maximizing the yield of ethanol. Response Surface Methodology (RSM) based central composite design was employed to obtain best combination of temperature, fermentation time and total soluble solids (TSS). The optimum conditions for ethanol yield were temperature ${ }^{\circ} 8^{\circ} \mathrm{C}$, TSS $15^{\circ}$ Brix and 6 days after fermentation. The model showed that the value of $R^{2}(0.9998)$ was high and $p$-value of interaction of variance was $<0.0001$. Hence the model can be said to be of highly significant.
\end{abstract}

Keywords: Ethanol, Fermentation time, Mead, Response Surface Methodology (RSM), Temperature, TSS

\section{INTRODUCTION}

Mead is one of the world's oldest alcoholic beverages, containing $8-18 \%(\mathrm{v} / \mathrm{v})$ of ethanol, which results from the alcoholic fermentation of diluted honey carried out by yeast. Though mead is the oldest fermented product being used by man yet it is difficult to find it commercially (Pereira et al., 2009) since mead producers face several problems, like delayed and arrested fermentation, production of off-flavours by the yeast and lack of uniformity of the final product.

Honey is a natural product, a highly concentrated solution of a complex mixture of sugars. It also contains small amounts of other constituents such as minerals, proteins, vitamins, organic acids, flavonoids, phenolic acids, enzymes and other phytochemicals. The components in honey responsible for its antioxidative effect are flavonoids, phenolic acids, ascorbic acid, catalase, peroxidase and carotenoids (Turkmen et al., 2006; Bertoncelj et al., 2007). The colour, flavour, aroma and yeast are important quality characteristics which inturn influence the quality of mead (Gupta and Sharma, 2009). Rock bees (Apis dorsata) are giant bees found all over India in sub-mountainous regions up to altitude of $2700 \mathrm{~m}$. This honey has higher amount of enzymes, amino acids and minerals than $A$. cerana and $A$. mellifera honey. Fermentation process has both the nonlinear and dynamic properties. Considerable attempts have been made by several researchers to propose a methodology based on mathematical models. Major problems of fermentation process are that they need a large number of experiments and often the models are very complicated to describe the experimental observation (Hajar et al., 2012).

Optimization of process condition is one of the most critical stages in the development of an efficient and economic bioprocess (Karuppaiya et al., 2009). The conventional one-factor-at-a-time approach of optimization is not only tiresome but also ignores to merge interaction of each factor. One of the most common optimization used in last two decades is the Response Surface Methodology (RSM). RSM is a powerful mathematical model with a collection of statistical techniques by which interaction between multiple processes variables can be identified with fewer experimental trials. It is widely used to examine and optimize the operational variables for experimental design, model developing, and test variable and condition optimization. There are various advantages in using statistical methodologies in terms of rapid and reliable short listing of process conditions, understanding interaction among them, and a tremendous reduction in total number of experiments, resulting in saving time, glassware, chemicals and manpower (Cheynier et al., 1983).

In spite of various advantages, statistical designs have been applied to only limited number of aerobic submerged and solid state fermentation and anaerobic submerged fermentation processes deal with a large number of variables, and there are several reports on the application of RSM for the production of primary and secondary metabolites through microbial fermentation (Karuppaiya et al., 2009). Although 
many advances in the developments of mead have been made over the last few years, particularly in terms of optimizing ethanol concentration, there is still scope for future development. The present study was aimed to find out the optimum fermentation condition for producing mead as a health drink. RSM was used for optimization of ethanol concentration less than five.

\section{MATERIALS AND METHODS}

Yeast strain and culture growth conditions: Saccharomyces cerevisiae (KF233529) has been isolated from honey and standardized in the Department of Agricultural Microbiology was used for this study. The yeast cells were grown in Yeast peptone dextrose agar (YPD), containing glucose 20g, peptone $10 \mathrm{~g}$, yeast extract $5 \mathrm{~g}$ and agar $20 \mathrm{~g}$ per litre. The culture was routinely maintained at $4^{\circ} \mathrm{C}$ on slants. Before use, the culture was transferred to YPD broth and incubated for $24 \mathrm{~h}$ at $27^{\circ} \mathrm{C}$.

Honey: In the present study, rock bee honey was obtained from a local bee keeper at north-east region of Dindugal district, Tamil Nadu.

Honey-must preparation and fermentation condition for mead fermentation: Rock bee ( $A$. dorsata) honey was diluted with tap water (35g: $85 \mathrm{~mL}$ ) and mixed to homogeneity. The insoluble solids were removed by filtering to obtain a clarified honey-must. Sulphur dioxide, in the form of potassium metabisulfite, was added up to a concentration of $100 \mathrm{mg} / \mathrm{L}$ of free $\mathrm{SO}_{2}$ to inhibit the bacterial growth. Starter culture was prepared by pre-growing the yeast culture in YPD broth for $24 \mathrm{hrs}$. Incubation was done at $27^{\circ} \mathrm{C}$ with gentle orbital shaker at $120 \mathrm{rpm}$. Above honey must was inoculated with $4 \%$ inoculum with an initial population of $10^{5}$ Colony-Forming Units (CFU/mL). Fermentation was carried out in $250 \mathrm{ml}$ Erlenmeyer flasks with $100 \mathrm{ml}$ honey must. Two days after aerobic fermentation, the Erlenmeyer flasks were water sealed.

Estimation of Ethanol: Ethanol content was estimated using Refractrometer (\%).

Experimental design and response surface methodology: Design Expert Software Version (8.0) was used to optimize the fermentation condition for Indian rock bee mead production. This software applies the principle of RSM to determine the optimal response. Three important factors, namely temperature (A), fermentation time (B) and TSS (C), considered as operating (independent) parameters, were selected to study their effect on ethanol production. Table 1 states the actual values and the coded values of the variables employed. Coded values of $+1,0$ and -1 correspond to high, medium and low values of variables, respectively. Ethanol percentage was regarded as the response or output variable (r). The central composite design (CCD) was used to access the effects of the three input independent parameters on the desired responses and build a second order (quadratic) model for the response variable (r). The statistically designed experiments comprised 8 factorial points, 6 axial points and 6 replicates at the centre points resulting in a total of 20 experiments. The ethanol percentage was observed from each of the 20 experiments analysed by Analysis of Variance (ANOVA) to determine the optimum conditions. The regression analysis was performed to fit the response.

\section{RESULTS AND DISCUSSION}

Interaction of factors and honey wine fermentation: In mead fermentations, the fermentation process is influenced by the temperature. But temperature tolerance for growth of yeast and fermentation is strongly strain dependent (Rousseau et al., 1992). In the honey wine fermentation, ethanol production was high at $28^{\circ} \mathrm{C}$ upto 6 days. The optimum yield for ethanol production was obtained at $28^{\circ} \mathrm{C}$. Ethanol production was decreased with the increasing temperature. The reason was that after a period of time (6 days) this high temperature $\left(34.73^{\circ} \mathrm{C}\right)$ inactivated the yeast cell. It was reported that ethanol producing yeast could grow rapidly at temperature $25-33^{\circ} \mathrm{C}$ (Ozcelik and Denli, 1996). At less than $25^{\circ} \mathrm{C}$ and more than $30^{\circ} \mathrm{C}$, it was not favourable temperature for our yeast strain therefore at these stress conditions ethanol productions was lowest. At $32^{\circ} \mathrm{C}$, the yeast cell was moderately activated and ethanol concentration was gradually increased with time upto 10 days. Therefore the yeast cells were very much affected by temperature. Temperature controls the cell viability, growth rate, exponential phase, enzyme activity and membrane function (Torija et al., 2003).

Fermentation is slow in a medium containing low sugar, whereas its speed increases in must which have $15^{\circ}$ Brix. Above this concentration, fermentation slows. Thus, an elevated amount of sugar hinders yeast growth and decreases the ethanol concentration (D'Amato et al., 2006). It is known that the high substrate concentrations may cause osmotic shock of the yeast cells and slow down the mass and heat transfer. A decline of the ethanol concentration could be noticed because of the exhaustion of the release glucose and the transition of the yeast metabolism

Table 1. Natural levels, codes and intervals of variation of the independent variables in the design of experiments.

\begin{tabular}{lccccccc}
\hline Process parameters & Codes & \multicolumn{9}{c}{ Levels } & \multicolumn{2}{c}{$\begin{array}{c}\text { Interval of } \\
\text { variation }\end{array}$} \\
\cline { 3 - 7 } & & $\mathbf{- 1 . 6 8 2}$ & $\mathbf{- 1}$ & $\mathbf{0}$ & $\mathbf{+ 1}$ & $\mathbf{+ 1 . 6 8 2}$ & 4 \\
\hline Temperature $\left({ }^{\circ} \mathrm{C}\right)$ & $\mathrm{A}$ & 21.27 & 24 & 28 & 32 & 34.72 & 4 \\
Fermentation time (days) & $\mathrm{B}$ & -0.72 & 2 & 6 & 10 & 12.72 & 10 \\
TSS $\left({ }^{\circ}\right.$ Brix) & $\mathrm{C}$ & -1.81 & 5 & 15 & 25 & 31.81 & 4 \\
\hline
\end{tabular}


Table 2. Central composite design matrix of process parameters of independent variables and their corresponding experimental and predicted yields of ethanol.

\begin{tabular}{|c|c|c|c|c|c|}
\hline \multirow[b]{2}{*}{ Run No. } & \multicolumn{3}{|c|}{ Independent variables } & \multicolumn{2}{|c|}{ Ethanol (\%) } \\
\hline & $\begin{array}{c}\text { Temperature } \\
\left({ }^{\circ} \mathrm{C}\right)\end{array}$ & $\begin{array}{c}\text { Fermentation } \\
\text { time (days) }\end{array}$ & $\begin{array}{c}\text { TSS } \\
\left({ }^{\circ} \text { Brix }\right)\end{array}$ & Observed & Predicted \\
\hline 1 & -1 & -1 & -1 & 0.35 & 0.32 \\
\hline 2 & +1 & -1 & -1 & 0.50 & 0.48 \\
\hline 3 & -1 & +1 & -1 & 2.05 & 2.06 \\
\hline 4 & +1 & +1 & -1 & 2.45 & 2.44 \\
\hline 5 & -1 & -1 & +1 & 2.40 & 2.39 \\
\hline 6 & +1 & -1 & +1 & 2.29 & 2.27 \\
\hline 7 & -1 & +1 & +1 & 3.51 & 3.52 \\
\hline 8 & +1 & +1 & +1 & 3.62 & 3.63 \\
\hline 9 & $-\alpha$ & 0 & 0 & 2.72 & 2.73 \\
\hline 10 & $+\alpha$ & 0 & 0 & 2.93 & 2.95 \\
\hline 11 & 0 & $-\alpha$ & 0 & 0.82 & 0.86 \\
\hline 12 & 0 & $+\alpha$ & 0 & 3.48 & 3.46 \\
\hline 13 & 0 & 0 & $-\alpha$ & 0.49 & 0.51 \\
\hline 14 & 0 & 0 & $+\alpha$ & 3.25 & 3.25 \\
\hline 15 & 0 & 0 & 0 & 4.81 & 4.85 \\
\hline 16 & 0 & 0 & 0 & 4.85 & 4.85 \\
\hline 17 & 0 & 0 & 0 & 4.89 & 4.85 \\
\hline 18 & 0 & 0 & 0 & 4.90 & 4.85 \\
\hline 19 & 0 & 0 & 0 & 4.83 & 4.85 \\
\hline 20 & 0 & 0 & 0 & 4.84 & 4.85 \\
\hline
\end{tabular}

Table 3. Analysis of variance (ANOVA) for ethanol production using CCD.

\begin{tabular}{lccccc}
\hline Source & Sum of squares & $\begin{array}{c}\text { Degrees } \\
\text { of freedom }\end{array}$ & Mean square & F value & P value \\
\hline Model & 48.02 & 9 & 5.34 & 4810.82 & $<0.0001$ \\
Temperature (A) & 0.06 & 1 & 0.06 & 53.86 & $<0.0001$ \\
Fermentation time (B) & 8.17 & 1 & 8.17 & 7367.51 & $<0.0001$ \\
TSS (C) & 9.04 & 1 & 9.04 & 8152.00 & $<0.0001$ \\
$\mathrm{AB}$ & 0.02 & 1 & 0.02 & 24.90 & 0.0005 \\
$\mathrm{AC}$ & 0.03 & 1 & 0.03 & 34.09 & 0.0002 \\
$\mathrm{BC}$ & 0.18 & 1 & 0.18 & 165.02 & $<0.0001$ \\
$\mathrm{~A}^{2}$ & 7.32 & 1 & 7.32 & 6601.84 & $<0.0001$ \\
$\mathrm{~B}^{2}$ & 13.05 & 1 & 13.05 & 11762.67 & $<0.0001$ \\
$\mathrm{C}^{2}$ & 15.90 & 1 & 15.90 & 14337.80 & $<0.0001$ \\
Residual & 0.01 & 10 & $1.109 \mathrm{E}-003$ & & \\
Lack of fit & $4.95 \mathrm{E}-003$ & 5 & $9.914 \mathrm{E}-004$ & 0.81 & 0.5895 \\
Pure error & $6.13 \mathrm{E}-003$ & 5 & $1.227 \mathrm{E}-003$ & & \\
Corrected total & 48.03 & 19 & & & \\
$\mathrm{R}^{2}=0.9998$ & Adjusted $\mathrm{R}^{2}=0.9996$ & & C.V $(\%)=1.11$ & \\
\hline
\end{tabular}

towards utilization of ethanol as a carbon source. Glucose and fructose utilization was almost completed within 6 days of fermentation time. The glucose and fructose consumption was in accordance with the results of ethanol concentration since the glucose and fructose was consumed as a carbon source by the yeast. Substrate inhibition significantly effect on ethanol yield and their results concerning the substrate inhibition were in agreement with the results in this study (Nikolic et al., 2009).

The 3D response surface plots described by the regression model were drawn to illustrate the effects of interaction of each independent variable (temperature, fermentation time and TSS) on the response variable 

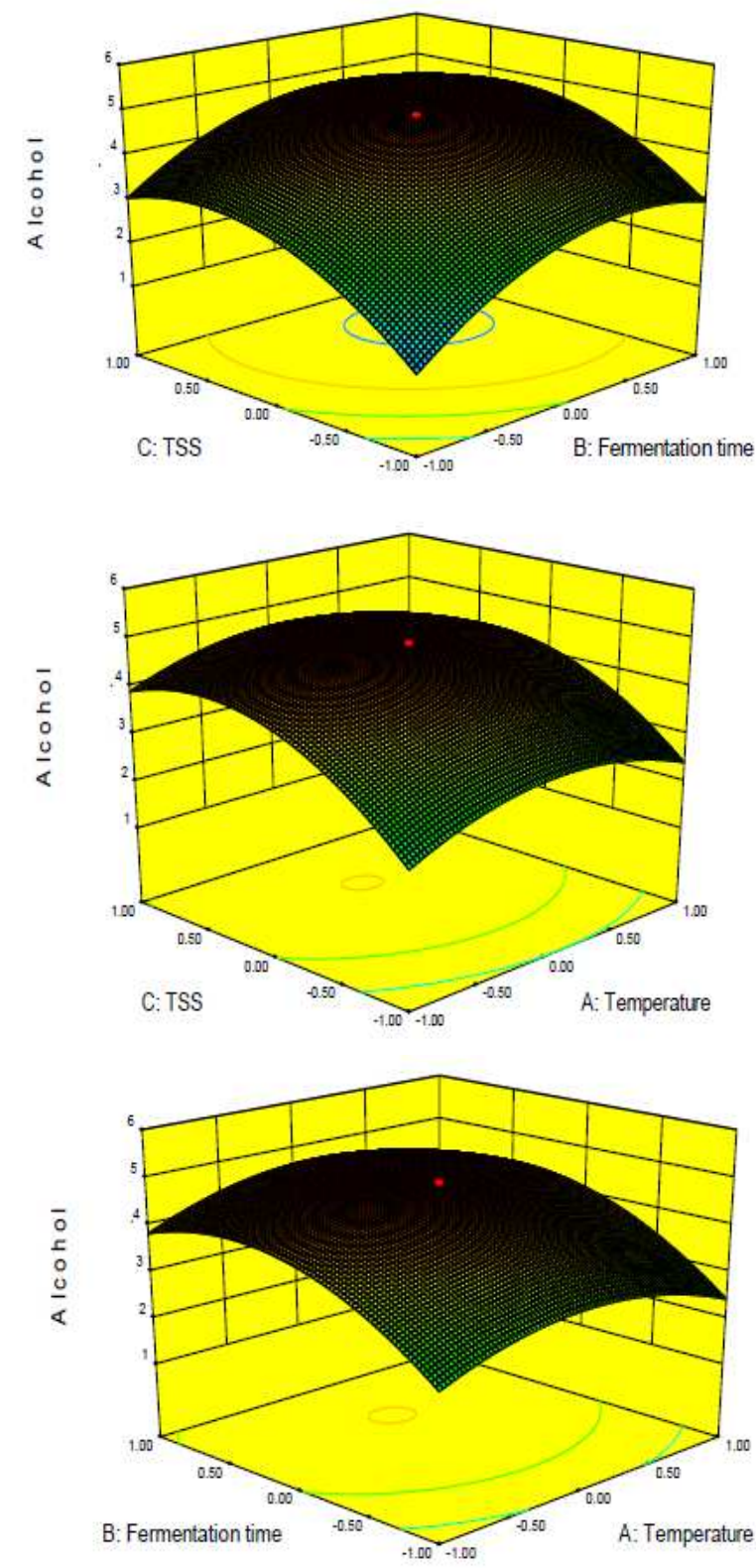

Fig. 1. Response surface curve showing the effects fermentation parameters on rock bee mead ethanol content (\%).

(Bocchini et al., 2002). The response surface plots with $3 \mathrm{D}$ response surface of the calculated model are shown in Fig. which indicates the relationship between the response and the experimental data. The ethanol yield was significantly affected by temperature, fermentation time and TSS where temperature produced greater effect. The point prediction tool of the software was used to determine the optimum values of the factors for maximum ethanol production: temperature $28^{\circ} \mathrm{C}$, fermentation time 6 days and TSS $15^{\circ}$ Brix. The result confirmed that the model was adequate for reflecting the expected optimization Hajar et al. (2012) also studied the fermentation parameters ( $\mathrm{pH}$, temperature, inoculums concentration, sugar concentration and time) for maximizing ethanol production. They reported that it could be achieved at the conditions when inoculum concentration $6-14 \%(\mathrm{v} /$ v), $\mathrm{pH}$ (4.0-6.0), sugar concentration (14-22 ${ }^{\circ}$ Brix), temperature $\left(24-32^{\circ} \mathrm{C}\right)$ and time of incubation (30-54 hrs). Ghosh et al. (2012) optimized the process condition for palm wine fermentation using response surface methodology. In this study temperature, TSS and fermentation time were considered as independent variables.

RSM analysis for the mead fermentation: The mead fermentation was carried out by controlling various fermentation parameters which were important for production of ethanol. The average of the triplicate measurements of the ethanol concentration are shown in Table 2. Optimum ethanol concentration $4.84 \%$ was determined at the optimum condition of $28^{\circ} \mathrm{C}$ temperature, $15^{\circ}$ Brix and after 6 days. Statistical significance of honey wine fermentation model is explained by analysis of variance (ANOVA). Nature of fit of the regression model is determined by the adjusted co-efficient of determination $\left(R^{2}\right.$ adj). The high value of $R^{2}$ adj 0.9996 indicates the goodness of fit of the regression equation. The predicted co-efficient of determination ( $\mathrm{R}^{2}$ pred) value was 0.990 .

The probability of $\mathrm{p}$-value for models of less than 0.05 indicate that models were significant, $p$-value less than 0.0001 indicate the models were highly significant. So our model p value was $<0.0001$ it was highly significant. The words lack of fit refers to the fact that the simple linear regression model may not adequately fit the data. Our $p$ value for lack of fit of model was insignificant it indicted that our experimental model system was statistically significant. Values for actual and predicted responses were very close because the correlation value, $\mathrm{R}^{2}=99.96 \%$ that means the experimental data could be accepted (Samah, 2008).

Applying the multiple regression analysis on the experiment, the response variables and the test variables are related by following second order polynomial equation:

Final equation in terms of coded factors $=+4.85$ $+0.06 * \mathrm{~A}+0.77 * \mathrm{~B}+0.81 * \mathrm{C}+0.05 * \mathrm{~A} * \mathrm{~B}-0.06 * \mathrm{~A} * \mathrm{C}$ $-0.15 * \mathrm{~B} * \mathrm{C}-0.71 * \mathrm{~A}^{2}-0.95 * \mathrm{~B}^{2}-1.05 * \mathrm{C}^{2}$

Final equation in terms of actual factors $=-37.86+2.51 *$ temperature $+0.86^{*}$ fermentation time $+0.46^{*}$ TSS $+3.67 \mathrm{E}-003 *$ temperature $*$ fermentation time $-1.71 \mathrm{E}$ $-003 *$ temperature $*$ TSS $-3.78 *$ fermentation time $*$ TSS $-0.04 *$ temperature $0.05 *$ Fermentation time ${ }^{2}-0.01 * \mathrm{TSS}^{2}$ Table 3 shows the response of the variables temperature, fermentation time, TSS, temperature ${ }^{2}$, fermentation time $^{2}, \mathrm{TSS}^{2}$ and fermentation time $\mathrm{x}$ TSS were highly significant with p-value of less than 0.0001. For temperature $\mathrm{x}$ TSS and temperature $\mathrm{x}$ fermentation time, $\mathrm{p}$ value $<0.05$ and therefore this value was significant. All the linear $\left(A^{2,} B^{2}\right.$ and $\left.C^{2}\right)$ and interactive (BC) effect of variables were highly significant for ethanol production (Table 4), as understood from their respective $p$ values $(p<0.0001)$. 
Table 4. Significance of the regression coefficients of the model

\begin{tabular}{lcccc}
\hline Factor & Coefficient estimate & Degrees of freedom & Standard error & p value \\
\hline Intercept & 4.85 & 1 & 0.01 & $<0.0001$ \\
Temperature (A) & 0.06 & 1 & $9.012 \mathrm{E}-003$ & $<0.0001$ \\
Fermentation time (B) & 0.77 & 1 & $9.012 \mathrm{E}-003$ & $<0.0001$ \\
TSS (C) & 0.81 & 1 & $9.012 \mathrm{E}-003$ & $<0.0001$ \\
$\mathrm{AB}$ & 0.05 & 1 & 0.01 & 0.0005 \\
$\mathrm{AC}$ & -0.06 & 1 & 0.01 & 0.0002 \\
$\mathrm{BC}$ & -0.15 & 1 & 0.01 & $<0.0001$ \\
$\mathrm{~A}^{2}$ & -0.71 & 1 & $8.773 \mathrm{E}-003$ & $<0.0001$ \\
$\mathrm{~B}^{2}$ & -0.95 & 1 & $8.773 \mathrm{E}-003$ & $<0.0001$ \\
$\mathrm{C}^{2}$ & -1.05 & 1 & $8.773 \mathrm{E}-003$ & $<0.0001$ \\
\hline
\end{tabular}

\section{Conclusion}

This study optimized the ethanol yield using RSM. The RSM allowed a rapid screening of the important influence factors and development of a polynomial model to optimize the process parameters for enhancing ethanol yield. Data obtained from experiment were analysed with RSM software (Version 8) gave the optimum ethanol yield $4.85 \%$ was determined at the optimum condition of temperature $28^{\circ} \mathrm{C}$, TSS $15^{\circ}$ Brix and 6 days after fermentation. The significant regression equation or model at the $5 \%$ level with correlation value $99.96 \%$ was also obtained. Since none had attempted so far, to optimize fermentation condition for getting maximum mead yield, the current study would be the pioneering report.

\section{ACKNOWLEDGEMENT}

The authors kindly acknowledge the funding granted by Indian counsil of Agricultural Research (ICAR) under the scheme "Application of microorganisms in Agriculture and allied sciences (AMAAS)".

\section{REFERENCES}

Bertoncelj, J., Dobersek, U., Jamnik, M. and Golob, T. (2007). Evaluation of the phenolic content, antioxidant activity and colour of Slovenian honey. Food Chemistry, 105: 822-828

Bocchini, D. A., Alves-Prado, H. F., Roberto, I. C., Gomes, E. and Silva, R. (2002). Optimization of xylanase production by Bacillus circulans D1 in submerged fermentation using response surface methodology. Proc. Biochem, 38: 727-731.

Cheynier, V., Feinberg, M., Chararas, C. and Ducauze, C. (1983). Application of response surface methodology to evaluation of bioconversion experimental conditions. Appl. Environ. Microbiol, 45(2): 634-639

D'Amato, D., Corbo, M. R., Nobile, M. A. D. and Sinigaglia, M. (2006). Effects of temperature, ammonium and glucose concentrations on yeast growth in a model wine system. International Journal of Food Science and Technology, 41: 1152-1157.

Ghosh, S., Chakraborty, R. and Raychaudhuri, U. (2012). Optimizing process conditions for palm (Borassus flabelliffer) wine fermentation using response surface
Methodology. International Food Research Journal, 19(4): 1633-1639.

Gupta, J. K. and Sharma, R. (2009). Production and quality characteristics of mead and fruit-honey wines: A review. Natural Product Radiance, 8(4): 345-355.

Hajar, N., Zainal, S., Atikah, O. and Tengku Elida, T. Z. M. (2012). Optimization of ethanol fermentation from pineapple peel extract using response surface methodology (RSM). World Academy of Science, Engineering and Technology, 72.

Karuppaiya, M., Sasikumar, E., Viruthagiri, T. and Vijayagopal, V. (2009). Optimization of process conditions using response surface methodology (RSM) for ethanol production from waste cashew apple juice by Zymomonas mobilis. Chemical Engineering Communications, 196: 1425-1435

Nikolic, S., Mojovic, L., Rakin, M. and Pejin, D. (2009). "Bioethanol production from corn meal by simultaneous enzymatic saccharification and fermentation with immobilized cells of Saccharomyces cerevisiae var. ellipsoideus". Fuel, 88: 1602-1607.

Ozcelik, F. and Denli, Y. (1996). Sarap mayalarinin teknolojik ozellikleri, Gida, 24(6): 385-389.

Pereira, A P., Dias, T., Andrade, J., Ramalhosa, E. and Estevinho, L. M. (2009). Mead production: Selection and characterization assays of Saccharomyces cerevisiae strains. Food and Chemical Toxicology, 47: 2057-2063

Rousseau, S., Rouleau, D., Yerushalmi, L. and Mayer, R. C. (1992). Effect of temperature on fermentation kinetics of waste sulfite liquor by Saccharomyces cerevisiae. Journal of Chemical Technology and Biotechnology, 53: 285-291.

Samah, A. G. A. (2008). Modification of formaldehyde method, optimisation of formaldehyde content in rastrelliger faughni and euthynnus affinis and storage studies, Master Degree. Malaysia: Universiti Teknologi MARA.

Torija, M. J., Beltran, G., Novo, M., Poblet, M., Manuel, J, Mas, G. A. and Roze, N. (2003). Effects of fermentation temperature and Saccharomyces species on the cell fatty acid composition and presence of volatile compounds in wine. International Journal of Food Microbiology, 85: 127- 136.

Turkmen, N., Sari, F., Poyrazoglu, E. S. and Velioglu, Y. S. (2006). Effects of prolonged heating on antioxidant activity and colour of honey. Food Chemistry, 95: 653-657. 